\title{
Methodical Approach to Assessing Innovative Development Efficiency of Regional Economic Systems in the Conditions of the Creative Economy Development
}

\author{
OLHA POPELO $^{1}$, SVITLANA TULCHYNSKA $^{2}$, OLGA GARAFONOVA $^{3}$, \\ LIUBOV KOVALSKA ${ }^{4}$, SEMEN KHANIN ${ }^{5}$
}

\author{
${ }^{1}$ Department of Management and Civil Service, Chernihiv Polytechnic National University, \\ Chernihiv, UKRAINE \\ ${ }^{2}$ Department of Economics and Entrepreneurship, National Technical University of Ukraine, \\ "Igor Sikorsky Kyiv Polytechnic Institute", Kyiv, UKRAINE \\ ${ }^{3}$ Department of Management, Kyiv National Economics University named after Vadym Hetman, \\ Kyiv, UKRAINE \\ ${ }^{4}$ Department of Entrepreneurship, Trade and Logistics, Lutsk National Technical University, \\ Lutsk, UKRAINE \\ ${ }^{5}$ Department of Management and Public Administration, IHE “Academician Yuriy Bugay \\ International Scientific and Technical University”, Kyiv, UKRAINE
}

\begin{abstract}
Modern globalization processes of economic development are increasingly focusing on the regional level of economic development. The regional economic systems are the basis of economic development, as evidenced by the practice of European countries. Innovative orientation is and remains important for creative economy development, because it is the innovative development of regional economic systems that allows to increase efficiency of the economic activity, to use available resources more rationally without harming the environment, to improve living standards and more. In turn, innovative orientation of economic development of regional economic systems requires the development of methodological approaches to assess the regional innovation efficiency. The outlined and others determined the relevance of the scientific research on the development of a methodological approach to assessing innovative development efficiency of regional economic systems, to which this article is devoted.

As a result of the research, a methodical approach to assessing the dynamics of innovation efficiency of regional economic systems in the conditions of the creative economy development, which provides for four stages of its implementation, was developed. This approach allows to objectively analyze innovation efficiency of regions by determining the integrated index of innovation efficiency and the coefficient of the innovation efficiency dynamics, as well as to determine the most influential indicators that will further develop mechanisms to enhance innovation processes in regional economic systems and to increase their innovative development efficiency. The proposed methodological approach to assessing innovative development efficiency of Polish voivodeships has been tested.
\end{abstract}

Key-Words: - globalization, economic development, innovative development efficiency, innovative activity, region, regional economic system, dynamics of changes, creative economy.

Received: January 20, 2021. Revised: June 4, 2021. Accepted: June 18, 2021. Published: July 7, 2021.

\section{Introduction}

In the conditions of the creative economy development, innovation processes continue to be relevant, because they are able to increase the competitiveness of regional economic systems in both domestic and international markets, thus providing them with subjectivity on the world stage. An integrated method is often used to assess the dynamics of innovation activity. This method, of course, has certain advantages, as it allows to take into account a large number of indicators of innovative development at the level of regional economic systems. In addition to the use of integrated methods, it is possible to divide the regions into certain clusters to develop further general strategic directions of their development through innovation. However, the main disadvantage of integrated calculations is that the 
dynamic changes can be estimated only by determining the changes between the values of integrated indices over many years.

Introduction of the newest technologies, modern conceptually-newest management systems, development of innovative production, including that is new in the market, provides development of subjects of business and causes new pushes to the innovative activity as a whole.

The innovative activity is a multifaceted process that involves a certain knowledge, focus, urgency, feasibility, efficiency and more. The innovative activity can be quantified through various economic indicators in scientific, educational, industrial spheres of the activity. At the same time, innovative development efficiency of regional economic systems is important. In the opinion of the authors, innovative development efficiency of regional economic systems should be understood as the effectiveness of innovation through the introduction of improved approaches to the production process and management of all spheres of production and economic activity, using the intellectual potential of regional economic systems.

Highlighting previously unresolved parts of the overall problem. Despite the large number of publications of foreign and domestic scientists on the evaluation of innovation, regional innovation development, the issues of determining the dynamics of innovation efficiency of regional economic systems in the conditions of the creative economy development are not sufficiently reflected in scientific research and require further research.

The purpose of the article is to develop scientific and applied tools for assessing innovative development efficiency of regional economic systems in the conditions of the creative economy development, taking into consideration the dynamics of innovation processes.

\section{Literature Review}

Many scientific works of domestic and foreign scientists are devoted to the study of modern innovative technologies, namely, the innovative development of regional economic systems: Aminova E. (2016) [1], Beilin I., Khomenko V., Tagirov M., Zinurova R., Saubanov K., Yakupova N. (2020) [2], Dubyna M., Zhavoronok A. (2021) [3], Fleischmann K., Daniel R., Welters R. (2017) [4], Gasparin M., Quinn M. (2020) [5], Ivanova N., Zhuk O. (2020) [6], Kharchenko Y., Dergaliuk B., Khanin S., Tkachenko T. (2021) [7], Lazarenko Y., Marhasova V., Tkalenko N. (2020) [8], Li D., Wei Y. D., Miao C., Wu Y., Xiao W. (2019) [9], Malik K.,
Jasińska-Biliczak A. (2018) [10], Malinoshevska K., Martyshyn D. (2021) [11], Ober J. (2020) [12], Parvin A., Beruvides M. (2020) [13], Plechero M., Chaminade C. (2016) [14], Revko A., Butko M. (2020) [15], Shkarlet S., Shtyrhun K. (2020) [16], Shynkaruk L., Ivanchenkova L. (2020) [17], Snieška V., Navickas V., Havierniková K., Okręglicka M., Gajda W. (2020) [18], Sudolska A., Łapińska J. (2020) [19], Tarasenko D., Tsyklauri O., Belei S. (2021) [20], Zakharin S., Stoyanova-Koval S., Kychko I. (2021) [21], Zwolak J. (2019) [22] and others.

British researchers Gasparin M. and Quinn M. argue that regional innovation systems (RIS) have become a political panacea for the countries seeking to develop their economies. Researchers claim that most RIS research comes from Western economies, which have created infrastructure and institutional networks of governance. Researchers have developed a model for understanding the characteristics of the creative ecosystem, as well as a modified policy dissemination model that allows for bottom-up policy development in countries with economies in transition [5].

Within the article written by Chinese scientists, the relationship between network capabilities and innovation development in the context of two types of innovation networks are examined, namely Scientific Knowledge Networks (SKNs) and Technology Knowledge Networks (TKNs). Focusing on two types of networking capabilities, namely acquisition capabilities and management capabilities, the authors use the spatial mode model to compare the impact of many factors on different spatial modes [10].

The study of Fleischmann K., Daniel R., Welters R. (Australia) examined whether those same innovation methodologies are used and can grow a regional economy, specifically in Townsville, Australia. The results of surveys and interviews indicate uncertainty about the specifics of innovative methodologies, especially with regard to the interaction with end users of services, but there is general support for their use in the wider business community. The results suggest that creative industries have a strong potential for regional economic development, in particular Townsville in northern Australia, but only if the creative sector is better sold to the wider business [4].

Polish scientist Ober J. considers the variables that influence the creation of innovations and analyses the selected factors of organizational culture in terms of their impact on the adoption of innovations in Polish IT companies. What is new here is the study of their impact separately at each 
stage of innovation. The aim was to assess the impact of selected factors of organizational culture on the implementation of innovations by workers of the Polish IT industry at different stages. Due to the complexity of different aspects of the study, a triangulation strategy was used, combining survey methods, research bureaus, expert opinions and statistical analysis [12].

Scientists Sudolska A., Lapinska J. prove that the innovative ability of the company is considered to be the main factor of its competitiveness in the long run. Therefore, it is increasingly important to understand the critical variable that underlies a company's innovation capabilities. The article explores these issues and contributes to the study of the factors that determine innovative capabilities of the company. Using the model for panel data, the study found that the factors influencing the innovative capacity of manufacturing enterprises in Poland are: inter-organizational cooperation, hiring employees in research and development, as well as internal costs of companies in R\&D [19].

Researchers from Lithuania, Slovakia and Poland in their article "Technical, information and innovation risks of Industry 4.0 in small and medium enterprises - the case of Slovakia and Poland" note that the implementation of the Industry 4.0 concept causes many risks, especially for small and medium enterprises (SMEs). The aim of the study is to diagnose and compare the risks associated with the implementation of Industry 4.0 in Slovakian and Polish SMEs with knowledge or experience of working in a cluster [18].

The most important goal of Zwolak J.'s research is to determine the regression dependence of sold new products and significantly improved goods on the flows of real and human capital in Polish industry. The results of the study show that the negative structure of human capital causes its poor use in Polish industry; while passive technology transfer, in particular new machines and tools, as well as vehicles, has been leading in shaping the relative level of innovative production in Polish industry [22].

E. Aminova, a researcher from Germany, notes that the technologies resulting from successful hightech mergers and acquisitions (M\&A) have great innovative potential. The proposed structure facilitates publicly available information and data for forecasting potential innovation activities of companies involved in high-tech mergers and acquisitions [1].

Scientists Parvin AG, Beruvides MG (USA) in their article note that the speed of innovation is an important factor in determining, influencing and dictating the speed of decision-making in the organization, which affects its success. Organizations can easily determine the rate of diffusion of technological innovation post-situ. A framework for field knowledge on the speed of technological innovation will help decision-makers in the organization, and will be useful in proactive strategy, policy, and resource management rather than reactive. The main purpose of this study is to outline the components needed to develop a framework to determine how accurately the diffusion rate of technological innovation can be predicted with partial diffusion data. The main component of these efforts is a review of models of partial diffusion of innovations [13].

\section{Methods}

Despite the widespread use of methodological approaches to assessing innovative development efficiency of regions, the development of a methodological approach to assessing the dynamics of innovation of regional economic systems in the conditions of the creative economy development remains relevant and requires further development. In the opinion of the authors, it is more reasonable to study dynamic changes by using the coefficient of dynamics of innovation efficiency of regional economic systems. This ratio makes it possible to assess the rate of change in innovative development efficiency of regional economic systems. But their calculation is preceded by the definition of an integrated index of innovation efficiency of regional economic systems. Thus, we consider in more detail the proposed methodological approach to assessing the dynamics of innovation of regional economic systems. The methodological approach includes four stages.

The first stage involves the justification of the study, which includes the selection of the object, purpose, objectives, principles and methods of evaluation. The object of research is the processes of the innovation activity of regions / voivodships. The purpose of the methodological approach is to carry out an objective analysis and evaluation of the dynamics of innovation efficiency of regional economic systems. To achieve this goal, the following tasks are distinguished:

- substantiation of evaluation indicators, their rationing and verification for correlations;

- calculation of the integrated index of innovation efficiency of regional economic systems;

- determination of the coefficient of dynamics of innovative development efficiency of regional economic systems; 
- approbation of the proposed methodological approach;

- summarization of the obtained results.

The methodological approach is based on such principles of its implementation as:

- compliance of the proposed mathematical and analytical model with the level of the object of study;

- achievement of the outlined goal with the help of the developed tasks of the methodical approach;

- reliability of statistical information and received calculations;

- validity of the use of mathematical methods and techniques;

- simplicity of calculations and clarity of the obtained research results;

- logic and sequence of the methodological approach.

The second stage of the methodological approach is preparatory. At this stage, the estimated indicators are determined. The main principles of determining evaluation indicators are:

- comparability of indicators over time, which provides for the possibility of assessing the innovative development efficiency of regions / voivodeships over time;

- adaptability, which provides for the possibility of making calculations for the regional economic systems of different countries (for example, Poland for the provinces and Ukraine for the regions);

- optimality, their number should not be too large, but, at the same time, provide an opportunity to reliably assess the object of study.

It should be noted that the list of evaluation indicators may change over time and adapt to changes in the statistical base or changes in the detail of the tasks of the methodological approach.

In the proposed methodological approach, in accordance with the outlined principles for the calculation of the integrated index of innovation efficiency of regions / voivodships, the following indicators were identified:

- the number of industrial enterprises that implemented innovations, units (x1);

- the amount of funding for innovation per capita, euro (x2);

- the volume of sold innovative products per 1 population, euro (x3);

- the volume of sold innovative products in $\%$ to the total volume of sold industrial products $(\mathrm{x} 4)$.

The next stage of the methodological approach is the analytical stage. At this stage, the calculations of integrated indices of regions / voivodships, the coefficient of dynamics of innovation efficiency of regional economic systems are carried out. Let's consider in more detail these indicators to be calculated.

Since the calculation of the integral index involves the identification of correlations, it is possible to confirm the validity of their choice, as the use of correlation matrices in the calculation of the integrated index makes it possible to eliminate possible linear dependencies for which matrices do not find solutions. Correlation matrices in accordance with the separation of the condition $|\mathrm{k}| \geq 0.7$ make it possible to distinguish a set of autocorrelation relationships between the statistics selected for evaluation. If the correlation condition is observed, the integral index is calculated. As the indicators have different dimensions, such as units of industrial enterprises, the euro and the percentage, this makes them mandatory. This procedure allows to preserve all functional connections between them and further guarantees the elimination of the influence of the indicators dimensionality on the results of the calculation of the integrated index of innovation efficiency of regions / voivodships. The following formula is used for rationing:

$$
\begin{gathered}
X_{i j}^{r}=\frac{X_{j i r}}{X_{j c p i r}}, \\
X_{i j}^{r}=\left(X_{\text {lir }}, X_{2 i r} \ldots X_{j i r}\right),
\end{gathered}
$$

where - the obtained normalized value of the $\mathrm{j}$-th indicator of innovation efficiency of the i-th region / voivodship $(j=1,2,3,4)$;

$\mathrm{r}-$ analyzed period (years) in this case $\mathrm{r}=1, \ldots$, 10), as the estimates are taken from 2000 to 2019;

$\mathrm{x}_{\mathrm{jir}}-$ the initial value of the $\mathrm{j}$-th partial indicator;

$\mathrm{x}_{\mathrm{jcpir}}-$ estimation of mathematical expectation of the $\mathrm{j}$-th selected estimation indicator of the $\mathrm{i}$-th region / voivodship for the studied period;

- matrix of defined evaluation indicators of innovative development efficiency of the region / voivodship.

$$
\mathrm{X}_{i}^{r}=\left(\begin{array}{llll}
\mathrm{x}_{1_{1}} & \mathrm{x}_{1_{2}} & \ldots & \mathrm{x}_{1_{10}} \\
\mathrm{x}_{2_{1}} & \mathrm{x}_{22} & \ldots & \mathrm{x}_{2_{10}} \\
\mathrm{x}_{3_{1}} & \mathrm{x}_{3_{2}} & \ldots & \mathrm{x}_{3_{10}} \\
\mathrm{x}_{4_{1}} & \mathrm{x}_{42} & \ldots & \mathrm{x}_{4_{10}}
\end{array}\right)
$$

where $\mathrm{x}_{11}, \ldots \mathrm{x}_{410}$ - standardized indicators for assessing innovation efficiency over a ten-year period.

This way determining the integrated index of innovation efficiency of regions / voivodeships also takes into consideration the impact factor $(\mathrm{K})$ of all 
four indicators when calculating the integrated index value.

$$
\mathrm{K}=\left[\left(\mathrm{X}_{1}^{\mathrm{T}} * \mathrm{X}_{1}\right)^{-1} * \mathrm{X}_{1}^{\mathrm{T}}\right]^{\mathrm{T}},
$$

The calculated value of the integrated index of innovation efficiency of regional economic systems makes it possible to calculate the coefficient of dynamics. The root-mean-square coefficient of the dynamics of this voivodship for the studied period (2010-2019) is determined by the formula:

$$
\mathrm{KDicp}=\sqrt{\left(\frac{I i r_{1}}{r r_{1}}\right)^{2}+\left(\frac{I i r_{2}}{r r_{2}}\right)^{2}+\cdots+\left(\frac{I i r_{n}}{r r_{n}}\right)^{2}}
$$

where Iir - the value of the integrated index of the $\mathrm{i}$-th voivodeship / region in a certain year $\mathrm{r}$ (from 2010-2019);

$\mathrm{rr}$ - the rank of voivodship / region according to the integrated index value of innovation efficiency in a certain year.
The coefficient of dynamics shows the rate of change of the rank of the region depending on the change of the generalized index of innovation efficiency of regional economic systems.

At the final stage of the methodological approach to assessing the innovation effectiveness of regional economic systems in the conditions of the creative economy development is to summarize the calculations, to highlight trends and measures to improve the efficiency of innovation. In addition, the grouping of regions can be used, which makes it possible to propose strategies for their further development in the direction of increasing the innovation activity of certain groups of regional economic systems.

Visualization of the stages of the proposed methodological approach to assessing innovative development efficiency of regional economic systems in the conditions of the creative economy development is presented in Fig. 1.

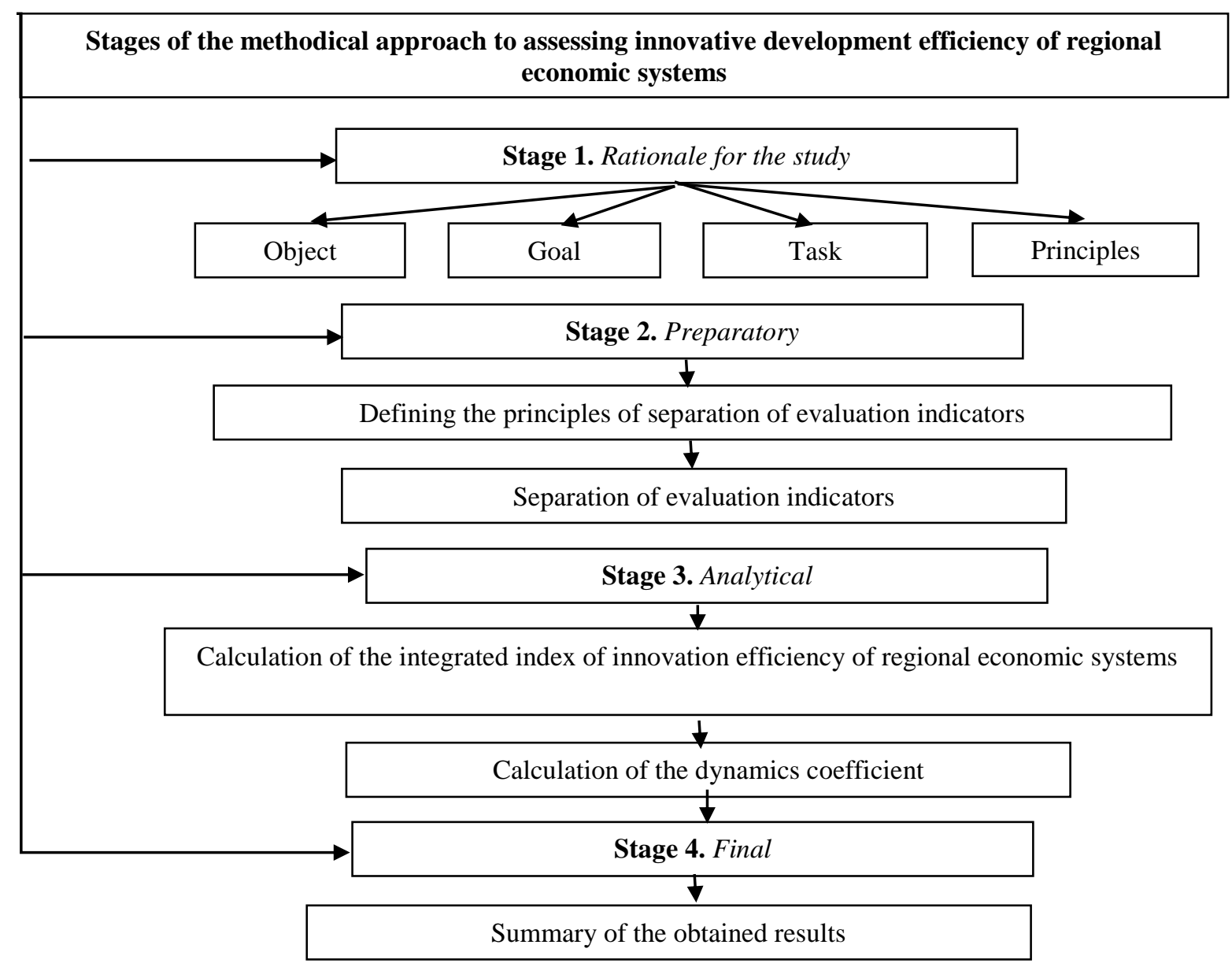

Fig.1. Stages of the methodical approach to assessing innovative development efficiency of regional economic systems in the conditions of the creative economy development

Source: suggested by the authors 


\section{Results and Discussions}

In accordance with the developed methodological approach to assessing innovative development efficiency of regional economic systems in the conditions of the creative economy development, it was tested for the voivodeships of Poland. In Table 1 , the calculated values of the integrated index according to the proposed methodological approach are shown.

Presented in Table 1 data make it possible to note that according to the average value of the integrated index of innovation efficiency for 20102019, the first place is occupied by the Pomeranian Voivodeship with the value of the integrated index 0.855. Swietokrzyskie is on the last step of the rating according to the average integrated index with an index value of 0.321 . The difference between the values of the index of these voivodeships is 2.7 times. Regions with a high average integrated index of innovation efficiency also include Masovian (0.853), Silesian (0.848), Greater Poland (0.805), and Lesser Poland (0.733) voivodships. The difference in the average integrated index in the first three voivodeships is rather insignificant. Apart from Swietokrzyski, Podlasie (0.325), Warmia and Mazury (0.344), Lublin (0.370) and Lubuskie (0.387) voivodeships with a low rating according to the value of the average integrated index. Visualization of the average integrated index of innovation efficiency of voivodeships for 2010-2019 is presented in Fig. 2.

Table 1. The value of the integrated index of innovation efficiency of Polish voivodships

\begin{tabular}{|c|c|c|c|c|c|c|c|c|c|c|c|c|}
\hline \multirow[b]{2}{*}{ Voivodeship } & \multicolumn{10}{|c|}{ The value of the integral index } & \multirow{2}{*}{ 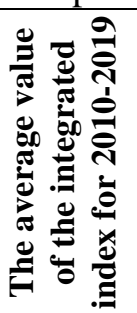 } & \multirow{2}{*}{ 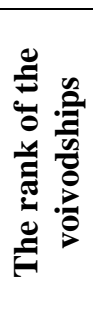 } \\
\hline & 2010 & 2011 & 2012 & 2013 & 2014 & 2015 & 2016 & 2017 & 2018 & 2019 & & \\
\hline Lower Silesia & 0,643 & 0,643 & 0,648 & 0,650 & 0,653 & 0,659 & 0,663 & 0,657 & 0,653 & 0,65 & 0,652 & 6 \\
\hline Kujawsko-Pon & 0,507 & 0,500 & 0,489 & 0,494 & 0,512 & 0,510 & 0,514 & 0,501 & 0,516 & 0,513 & 0,506 & 9 \\
\hline Lublin & 0,365 & 0,365 & 0,368 & 0,374 & 0,367 & 0,372 & 0,379 & 0,381 & 0,36 & 0,373 & 0,370 & 13 \\
\hline Lubuskie & 0,388 & 0,389 & 0,389 & 0,388 & 0,392 & 0,384 & 0,384 & 0,383 & 0,381 & 0,391 & 0,387 & 12 \\
\hline Lodzkie & 0,598 & 0,599 & 0,602 & 0,600 & 0,591 & 0,603 & 0,603 & 0,589 & 0,586 & 0,567 & 0,594 & 7 \\
\hline Lesser Poland & 0,716 & 0,721 & 0,736 & 0,743 & 0,744 & 0,74 & 0,735 & 0,738 & 0,728 & 0,724 & 0,733 & 5 \\
\hline Masovian & 0,846 & $\mathbf{0 , 8 4 8}$ & 0,856 & 0,846 & $\mathbf{0 , 8 4 3}$ & 0,856 & $\mathbf{0 , 8 6}$ & \begin{tabular}{|ll}
0,87 \\
\end{tabular} & 0,848 & 0,856 & $\mathbf{0 , 8 5 3}$ & 2 \\
\hline Opole Provi & 0,386 & 0,389 & 0,384 & 0,397 & 0,39 & 0,393 & 0,384 & 0,394 & 0,39 & 0,391 & 0,390 & 11 \\
\hline Podkarpackie Province & 0,575 & 0,581 & 0,587 & 0,579 & 0,587 & 0,579 & 0,591 & 0,584 & 0,579 & 0,582 & 0,582 & 8 \\
\hline Podlasie & 0,324 & 0,328 & 0,331 & 0,326 & 0,321 & 0,323 & 0,324 & 0,327 & 0,319 & 0,327 & 0,325 & 15 \\
\hline Pomeranian & $\mathbf{0 , 8 4 3}$ & 0,844 & 0,851 & $\mathbf{0 , 8 5 3}$ & $\mathbf{0 , 8 5 7}$ & $\mathbf{0 , 8 6 5}$ & $\mathbf{0 , 8 7}$ & $\mathbf{0 , 8 6 2}$ & 0,857 & 0,854 & $\mathbf{0 , 8 5 5}$ & 1 \\
\hline Silesian & $\mathbf{0 , 8 4 2}$ & $\mathbf{0 , 8 4 8}$ & 0,854 & $\mathbf{0 , 8 5}$ & $\mathbf{0 , 8 4 4}$ & 0,849 & $\mathbf{0 , 8 4 1}$ & 0,849 & $\mathbf{0 , 8 4 7}$ & 0,851 & $\mathbf{0 , 8 4 8}$ & 3 \\
\hline Swietokrzyskie & 0,317 & 0,318 & 0,324 & 0,315 & 0,324 & 0,317 & 0,322 & 0,329 & 0,321 & 0,321 & 0,321 & 16 \\
\hline Warmia and Mazury & 0,339 & 0,342 & 0,342 & 0,343 & 0,340 & 0,346 & 0,345 & 0,349 & 0,349 & 0,343 & 0,344 & 14 \\
\hline Greater Poland & 0,795 & 0,795 & 0,794 & 0,814 & 0,811 & 0,808 & 0,824 & 0,803 & 0,803 & 0,806 & 0,805 & 4 \\
\hline West Pomeranian & 0,432 & 0,433 & 0,436 & 0,431 & 0,435 & 0,429 & 0,437 & 0,421 & 0,427 & 0,416 & 0,430 & 10 \\
\hline $\begin{array}{l}\text { The arithmetic mean value } \\
\text { of the integrated index by } \\
\text { voivodships }\end{array}$ & 0,562 & 0,563 & 0,563 & 0,565 & 0,567 & 0,565 & 0,560 & 0,560 & 0,562 & 0,562 & 0,563 & - \\
\hline
\end{tabular}

Source: calculated by the authors according to the proposed methodological approach 


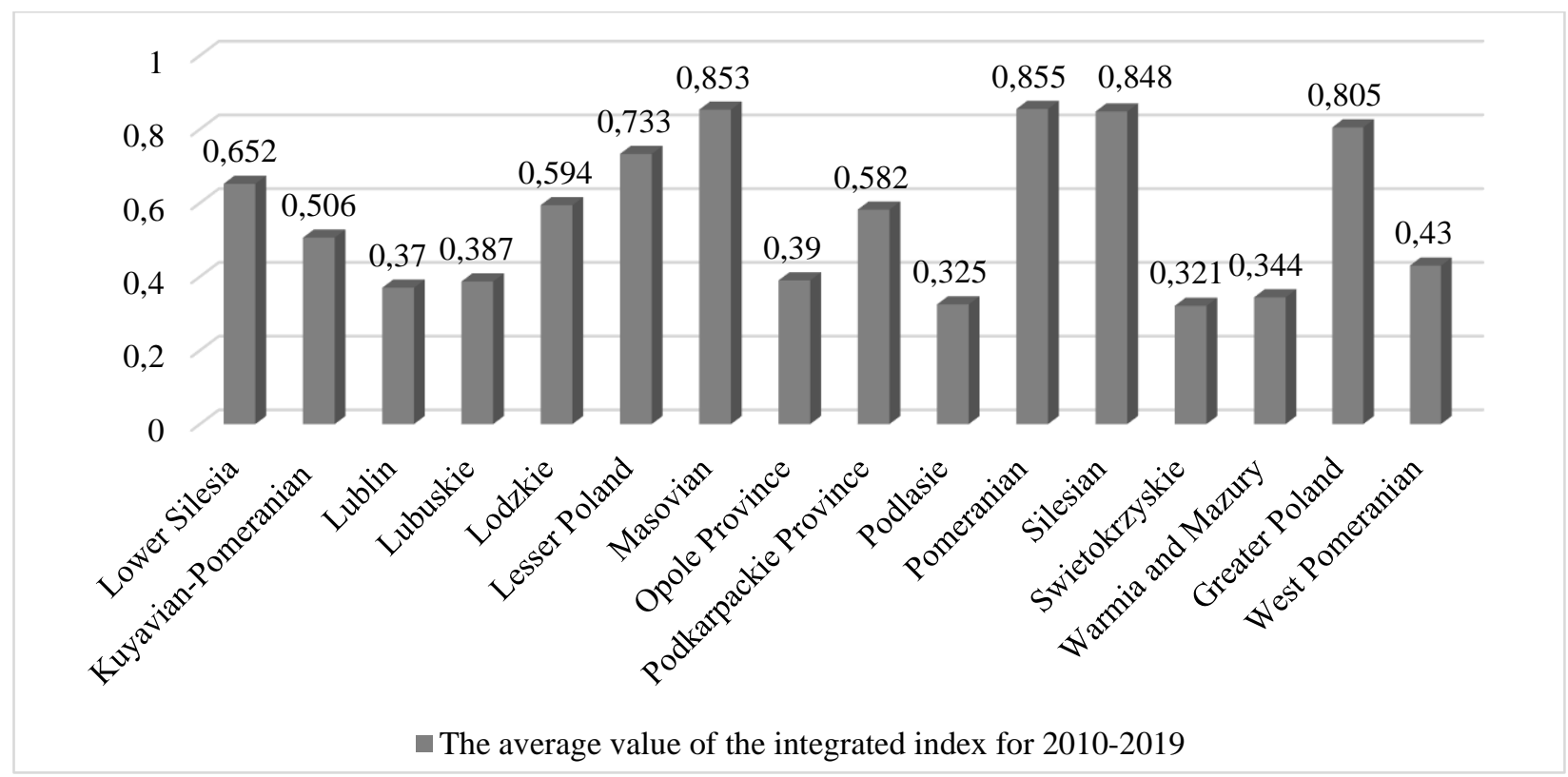

Fig.2. Average integrated index of innovation efficiency of voivodeships for 2010-2019.

Source: constructed by the authors based on the results of integrated index calculations

We study the changes in the integrated index for all voivodeships by year and we can note that from 2010 to 2014 there was a slight but steady increase in the arithmetic mean index of innovation efficiency of voivodeships (Fig. 3). In 2014, the arithmetic mean value of the integrated index was 0.567 , the lowest values fall on 2016-2017 at the level of 0.560. In 2018-2019, the arithmetic mean value of the integrated index for all voivodeships was 0.562 , which corresponds to the value of the index in 2010. Also, these values are less than the value of the generalized arithmetic mean integrated index for the country, equal to 0.563 .

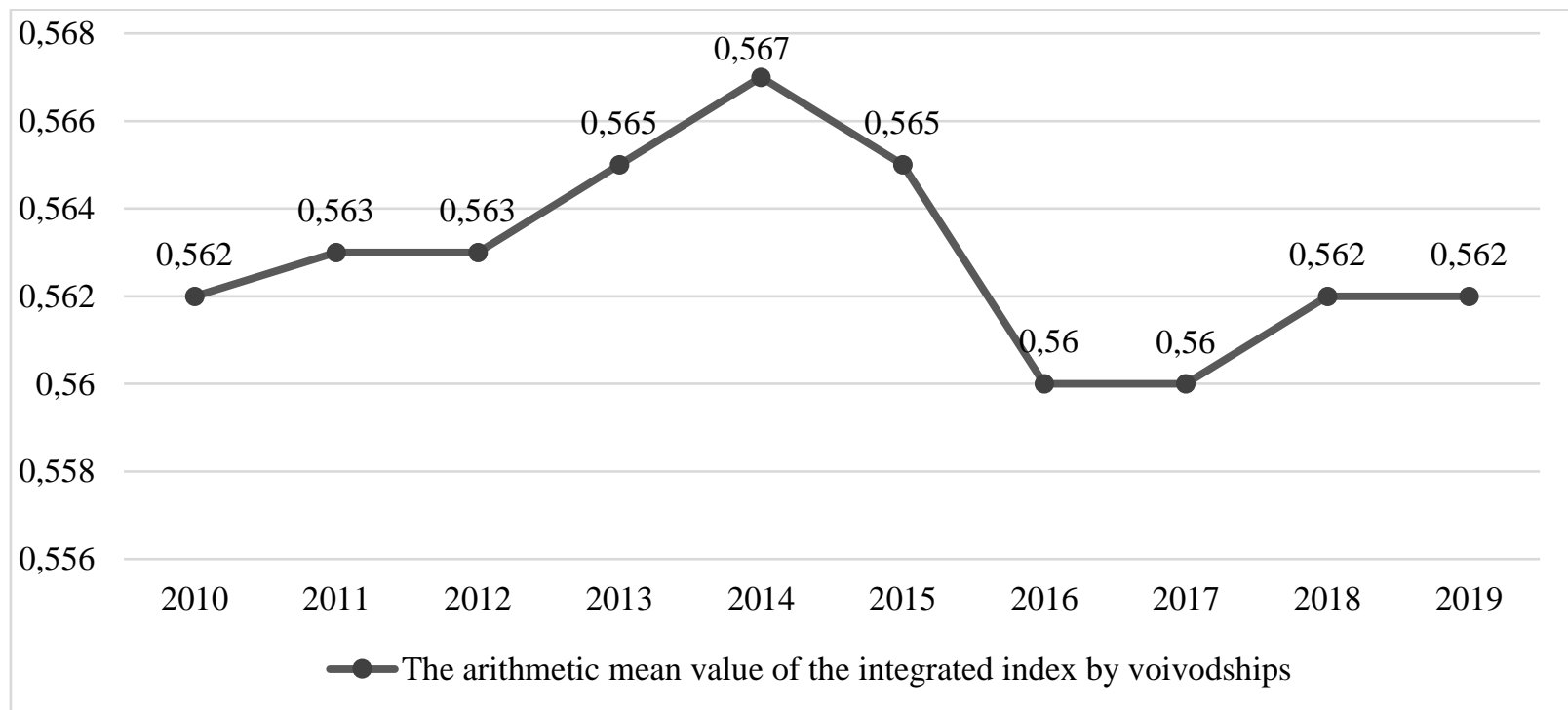

Fig.3. The arithmetic mean value of the integrated index of innovation efficiency by voivodships Source: constructed by the authors based on the results of the integrated index calculations

It should be noted that when calculating the integrated index of innovation efficiency of regions / voivodships, the impact factor was also taken into consideration (see Formula 4). The calculations make it possible to note that for most regions the most influential indicator is the amount of funding for innovation per capita (x2), which, in turn, necessitates increased funding for innovation to increase innovation efficiency of regional economic systems (Table 2). 
Table 2. Grouping of voivodeships by values of the most influential indicators on the integrated index of innovation efficiency

\begin{tabular}{|c|c|c|c|c|}
\hline & $\begin{array}{c}\text { The first indicator of the } \\
\text { degree of influence }\end{array}$ & $\begin{array}{l}\text { The second most } \\
\text { important } \\
\text { indicator }\end{array}$ & $\begin{array}{c}\text { The third most } \\
\text { important } \\
\text { indicator }\end{array}$ & $\begin{array}{c}\text { The fourth most } \\
\text { important } \\
\text { indicator } \\
\end{array}$ \\
\hline $\begin{array}{c}\text { number of } \\
\text { industrial } \\
\text { enterprises that } \\
\text { implemented } \\
\text { innovations, units } \\
\left(\mathrm{x}_{1}\right)\end{array}$ & $\begin{array}{l}\text { Lodzkie, Swietokrzyskie, } \\
\text { Warmia and Mazury }\end{array}$ & $\begin{array}{l}\text { Lublin, } \quad \text { Opole } \\
\text { Province, } \\
\text { Podkarpackie } \\
\text { Province, Silesian }\end{array}$ & $\begin{array}{lr}\text { Lower } & \text { Silesia, } \\
\text { Kujawsko- } & \\
\text { Pomorskie, } & \\
\text { Lubuskie, Masovian, } \\
\text { Podlasie, } \\
\text { Pomeranian, Greater } \\
\text { Poland, } \\
\text { Pomeranian }\end{array}$ & Lesser Poland \\
\hline $\begin{array}{c}\text { volume of } \\
\text { financing of the } \\
\text { innovative activity } \\
\text { per } 1 \text { person, euro } \\
\left(\mathrm{x}_{2}\right)\end{array}$ & $\begin{array}{l}\text { Lower Silesia, Kujawsko- } \\
\text { Pomorskie, Lesser Poland, } \\
\text { Masovian, Podkarpackie } \\
\text { Province, Silesian, Greater } \\
\text { Poland }\end{array}$ & $\begin{array}{l}\text { Lubuskie, Podlasie, } \\
\text { Pomeranian, } \\
\text { Swietokrzyskie, West } \\
\text { Pomeranian }\end{array}$ & $\begin{array}{lr}\text { Lodzkie, } & \text { Opole } \\
\text { Province, } & \text { Warmia } \\
\text { and Mazury } & \end{array}$ & Lublin \\
\hline $\begin{array}{l}\text { volume of sold } \\
\text { innovative } \\
\text { products, per } 1 \\
\text { person, euro }\left(\mathrm{x}_{3}\right)\end{array}$ & $\begin{array}{l}\text { Lublin, Lubuskie, Opole } \\
\text { Province, Podlasie, } \\
\text { Pomeranian, } \\
\text { Pomeranian }\end{array}$ & $\begin{array}{l}\text { Lower Silesia, } \\
\text { Kujawsko-Pomorskie, } \\
\text { Lodzkie, Masovian, } \\
\text { Warmia and Mazury, } \\
\text { Greater Poland }\end{array}$ & $\begin{array}{l}\text { Lesser Poland, } \\
\text { Podkarpackie } \\
\text { Province, Silesian }\end{array}$ & Swietokrzyskie \\
\hline $\begin{array}{l}\text { volume of sold } \\
\text { innovative products } \\
\text { in\% to the total } \\
\text { volume of sold } \\
\text { industrial products } \\
\left(\mathrm{x}_{4}\right)\end{array}$ & - & Lesser Poland & $\begin{array}{l}\text { Lublin, } \\
\text { Silesian, } \\
\text { Swietokrzyskie }\end{array}$ & $\begin{array}{l}\text { Lower Silesia } \\
\text { Kujawsko- } \\
\text { Pomorskie, } \\
\text { Lubuskie } \\
\text { Lodzkie, Masovian, } \\
\text { Opole Province, } \\
\text { Podkarpackie } \\
\text { Province } \\
\text { Podlasie, } \\
\text { Pomeranian, } \\
\text { Silesian, } \\
\text { Warmia } \\
\text { Mazury, Greater } \\
\text { Poland } \\
\text { West Pomerania } \\
\end{array}$ \\
\hline
\end{tabular}

\section{Source: grouped by authors based on the results of calculations of impact factors}

In general, according to the calculated integrated indices of innovation efficiency by years by voivodships, it can be noted that the values of integrated indices do not change significantly. This is also demonstrated by the ranks of voivodeships in terms of the integrated indices values. Thus, such seven voivodeships as: Lower Silesia (6th place in the rank of integrated indices), KujawskoPomorskie (9th place in rank), Lublin (13th place in rank), Lesser Poland (5th place in rank), Warmia and Mazury (14th place in the rank), Greater Poland (4th place in the rank), West Pomeranian (10th place in the rank) during the study period did not change the ranking positions. Six more voivodeships changed the ranking during the studied period from 2010-2019, but not by more than one neighboring step. Such voivodeships include Lubuskie (ranked 12th and 11th according to the value of the integrated index), Lodzkie (7th and 8th place in the rank), Opole Province (11-12th place), Podkarpackie Province (8-7th place), Podlasie (1516th place), Swietokrzyskie (16th-15th place).

The largest changes in the rankings according to the values of integrated indices for the studied period of time occurred in the top three in Masovian, Pomeranian and Silesian. This, in turn, is reflected in the values of the dynamic's coefficients (Table 3). 
Table 3. The value of the dynamic's coefficient of the voivodeships of Poland

\begin{tabular}{|l|c|c|c|c|c|c|c|c|c|c|c|}
\hline \multirow{2}{*}{ Voivodeship } & \multicolumn{9}{|c|}{ Ranks of regions according to the integrated index of innovation } & $\begin{array}{c}\text { The average } \\
\text { efficiency } \\
\text { value of CD for } \\
\mathbf{2 0 1 0 - 2 0 1 9 .}\end{array}$ \\
\cline { 2 - 17 } & $\mathbf{2 0 1 0}$ & $\mathbf{2 0 1 1}$ & $\mathbf{2 0 1 2}$ & $\mathbf{2 0 1 3}$ & $\mathbf{2 0 1 4}$ & $\mathbf{2 0 1 5}$ & $\mathbf{2 0 1 6}$ & $\mathbf{2 0 1 7}$ & $\mathbf{2 0 1 8}$ & $\mathbf{2 0 1 9}$ & $\mathbf{2 0 1 0}$ \\
\hline Lower Silesia & 6 & 6 & 6 & 6 & 6 & 6 & 6 & 6 & 6 & 6 & 0,266 \\
\hline Kujawsko-Pomorskie & 9 & 9 & 9 & 9 & 9 & 9 & 9 & 9 & 9 & 9 & 0,169 \\
\hline Lublin & 13 & 13 & 13 & 13 & 13 & 13 & 13 & 13 & 13 & 13 & 0,103 \\
\hline Lubuskie & 11 & 12 & 11 & 12 & 11 & 12 & 12 & 12 & 12 & 12 & 0,113 \\
\hline Lodzkie & 7 & 7 & 7 & 7 & 7 & 7 & 7 & 7 & 7 & 8 & 0,223 \\
\hline Lesser Poland & 5 & 5 & 5 & 5 & 5 & 5 & 5 & 5 & 5 & 5 & 0,328 \\
\hline Masovian & 1 & 2 & 1 & 3 & 3 & 2 & 2 & 1 & 2 & 1 & 0,682 \\
\hline Opole Province & 12 & 11 & 12 & 11 & 12 & 11 & 11 & 11 & 11 & 11 & 0,116 \\
\hline Podkarpackie Province & 8 & 8 & 8 & 8 & 8 & 8 & 8 & 8 & 8 & 7 & 0,207 \\
\hline Podlasie & 15 & 15 & 15 & 15 & 16 & 15 & 15 & 16 & 16 & 15 & 0,083 \\
\hline Pomeranian & 2 & 3 & 3 & 1 & 1 & 1 & 1 & 2 & 1 & 2 & 0,709 \\
\hline Silesian & 3 & 1 & 2 & 2 & 2 & 3 & 3 & 3 & 3 & 3 & 0,558 \\
\hline Swietokrzyskie & 16 & 16 & 16 & 15 & 16 & 16 & 15 & 15 & 16 & & 0,081 \\
\hline Warmia and Mazury & 14 & 14 & 14 & 14 & 14 & 14 & 14 & 14 & 14 & 14 & 0,092 \\
\hline Greater Poland & 4 & 4 & 4 & 4 & 4 & 4 & 4 & 4 & 4 & 4 & 0,403 \\
\hline West Pomeranian & 10 & 10 & 10 & 10 & 10 & 10 & 10 & 10 & 10 & 10 & 0,136 \\
\hline
\end{tabular}

Source: calculated by the authors according to the proposed methodological approach

The dynamics coefficient is directly dependent on changes in the integrated index of innovation efficiency of regional economic systems and changes in the ranks of regions. Since most voivodeships did not change ranks at all in terms of the values of the integrated index for a long period, or they were insignificant and represented a change of only one step, the values of the dynamics coefficient directly illustrate this. Thus, the largest dynamics coefficients were the three leading regions, which changed their positions in the ranking almost every year.

\section{Conclusion}

The authors proposed the methodological approach to assessing innovative development efficiency of regional economic systems in the conditions of the creative economy development, which, unlike existing ones, involves four stages of its formation, namely: justification of the study (separation of object, purpose, objectives, principles of approach), the preparatory stage (separation of evaluation indicators in accordance with the principles put forward to them), the analytical stage (implementation using selected mathematical methods of calculations of the integrated index of innovation efficiency of regional economic systems and coefficient of dynamics of innovation efficiency), the final stage (summation of calculation results). The implementation of such calculations makes it possible both to assess innovative development efficiency of regional systems, and to determine dynamic changes using the dynamics coefficient of innovation efficiency.

The approbation in the Polish voivodeships and the obtained results make it possible to note that the regions with the highest value of the integrated index of innovation efficiency, namely Masovian, Pomeranian and Silesian voivodships, have the highest dynamics coefficient.

The proposed methodological approach to assessing innovation efficiency of regional economic systems in the conditions of the creative economy development can be used for further applied development and the identification of mechanisms of influence and stimulators of innovation efficiency of regions.

\section{References:}

[1] Aminova, E. (2016). Forecasting potential innovation activities in high-tech industries triggered by merger and acquisition deals: A framework of analysis. European Journal of Futures Research, 4(1), 5.

[2] Beilin, I. L., Khomenko, V. V., Tagirov, M. Sh., Zinurova, R. I., Saubanov, K. R., Yakupova, N. M. (2020). The impact of innovations in the production of biologically valuable food products on supply chain management in the regional economy. International Journal of Supply Chain Management, 9(4), pp. 758-764.

[3] Dubyna, M., Zhavoronok, A., Kudlaieva, N., Lopashchuk, I. (2021). Transformation of household credit behavior in the conditions of digitalization of the financial services market. 
Journal of Optimization in Industrial Engineering, 14(1), pp. 97-102.

[4] Fleischmann, K., Daniel, R., Welters, R. (2017). Developing a regional economy through creative industries: innovation capacity in a regional Australian city. Creative Industries Journal, 10(2), pp. 119-138.

[5] Gasparin, M., Quinn, M. (2020). Designing regional innovation systems in transitional economies: A creative ecosystem approach. Growth and Change, pp. 1-20.

[6] Shkarlet, S., Ivanova, N., Popelo, O., Dubina, M., Zhuk, O. (2020). Infrastructural and Regional Development: Theoretical Aspects and Practical Issues. Studies of Applied Economics, 38-3(1). http://dx.doi.org/10.25115/eea.v38i4.4002.

[7] Popelo, O., Tulchynska, S., Kharchenko, Y., Dergaliuk, B., Khanin, S., Tkachenko, T. (2021). Systemic Approach to Assessing Sustainable Development of the Regions. Journal of Environmental Management and Tourism, XII, 3(51), pp. 742-753. DOI:10.14505/jemt.v12.3(51).13.

[8] Lazarenko, Y., Garafonova, O., Marhasova, V., Tkalenko, N., Grigashkina, S. (2020). Exploring Strategic Directions for the Local Innovation Ecosystem Development in the Mining Industry. E3S Web of Conferences, 174, 02001.

[9] Li, D., Wei, Y. D., Miao, C., Wu, Y., Xiao, W. (2019). Innovation, network capabilities, and sustainable development of regional economies in China. Sustainability, 11(17), 4770.

[10] Malik, K., Jasińska-Biliczak, A. (2018). Innovations and other processes as identifiers of contemporary trends in the sustainable development of SMEs: The case of emerging regional economies. Sustainability, 10(5), 1361.

[11] Malinoshevska, K., Martyshyn, D., Perestyuk, I., Panchenko, S., Omarov, A. (2021). Management of Financial and Economic Development of Border Regions of Ukraine. WSEAS Transactions on Business and Economics, 18, pp. 595-605.

[12] Ober, J. (2020). Innovation adoption: Empirical analysis on the example of selected factors of organizational culture in the it industry in Poland. Sustainability, 12(20), pp. 1-25.

[13] Parvin, A. J., Jr., Beruvides, M. G. (2020). Insitu innovation diffusion rate forecasting. ASEM 41st International Annual Conference Proceedings "Leading Organizations through Uncertain Times" 202041st International
Annual Conference of the American Society for Engineering Management: Leading Organizations through Uncertain Times. https://www.scopus.com/record/display.uri?eid $=2$-s 2.0 -

$85101658316 \&$ origin $=$ resultslist \&sort=plf -

$\mathrm{f} \& \mathrm{src}=\mathrm{s} \& \mathrm{st} 1=\& \mathrm{st} 2=\& \mathrm{sid}=842 \mathrm{~d} 6 \mathrm{de} 18 \mathrm{f} 604 \mathrm{~b} 339$ ba39feedb39c5d3\&sot=b\&sdt=b\&sl=30\&s=TI TLE\%28forecasting+innovations\%29\&relpos= $6 \&$ citeCnt $=0$ \&search Term $=$.

[14] Plechero, M., Chaminade, C. (2016). The role of regional sectoral specialisation on the geography of innovation networks: A comparison between firms located in regions in developed and emerging economies. International Journal of Technological Learning, Innovation and Development, 8(2), pp. 148-171.

[15] Revko, A., Butko, M., Popelo, O. (2020). Methodology for Assessing the Inflence of Cultural Infrastructure on Regional Development in Poland and Ukraine. Comparatie Economic Research. Central and Eastern Europe, 23(2), pp. 21-39.

[16] Shkarlet, S., Dubyna, M., Shtyrhun, K. (2020). Transformation of the Paradigm of the Economic Entities Development in Digital Economy. WSEAS TRANSACTIONS on ENVIRONMENT and DEVELOPMENT, 6, pp. 413-422.

[17] Shynkaruk, L., Ivanchenkova, L., Kychko, I., Kartashova, O., Melnyk, Y., Ovcharenko, T. (2020). Managing the economy's investment attractiveness of the state as a component of international business development. International Journal of Management (IJM), 11 (5), pp. 240-251.

[18] Snieška, V., Navickas, V., Havierniková, K., Okręglicka, M., Gajda, W. (2020). Technical, information and innovation risks of industry 4.0 in small and medium-sized enterprises - Case of Slovakia and Poland. Journal of Business Economics and Management, 21(5), pp. 12691284.

[19] Sudolska, A., Łapińska, J. (2020). Exploring determinants of innovation capability in manufacturing companies operating in Poland. Sustainability, 12(17), 7101.

[20] Tarasenko, D., Tsyklauri, O., Belei, S., Riabenka, M., Mazurkevych, I., Bashlai, S. (2021). Social-economic Development of the United Territorial Communities and Development of a Strategy for Sustainable Development (case of Ukraine). WSEAS 
Transactions on Business and Economics, 18, pp. 581-594.

[21] Zakharin, S., Stoyanova-Koval, S., Kychko, I., Marhasova, V., Shupta, I. (2021). Strategic Management of the Investment Process in the Agricultural Sector (for Example, Agricultural Enterprises and the Food Industry). Journal of Optimization in Industrial Engineering (JOIE), 14(1), pp. 209-218. URL: http://www.qjie.ir/article_677867.html.

[22] Zwolak, J. (2019). Innovations in the industry of Poland. WSEAS Transactions on Business and Economics, 16, pp. 39-46.

\section{Contribution of Individual Authors to the Creation of a Scientific Article (Ghostwriting \\ Policy)}

Olha Popelo - The genesis of scientific opinion on the existing approaches to assessing innovative development at the regional level by domestic and foreign scientists has been studied; the statistical information is analyzed and the list of estimation indicators of innovative development efficiency of regional economic systems is offered;

Svitlana Tulchynska - Methodological bases of substantiation of the offered methodical approach of an estimation of innovative development efficiency of regional economic systems in the conditions of the creative economy development are allocated;

Olga Garafonova - The algorithm of stages of realization of the offered methodical approach is constructed;

Liubov Kovalska - The approbation of the developed methodical approach in the part of calculations of integrated indices of innovative development efficiency on an example of voivodeships of Poland is carried out;

Semen Khanin - The developed methodological approach was tested in terms of calculating the coefficient of the dynamics of innovation efficiency and identifying the ranks of voivodeships by years in accordance with the calculated values of the integrated index on the example of Polish voivodships.

\section{Creative Commons Attribution License 4.0}

\section{(Attribution 4.0 International, CC BY 4.0)}

This article is published under the terms of the Creative Commons Attribution License 4.0 https://creativecommons.org/licenses/by/4.0/deed.en _US 